\title{
Difalia em um bovino
}

\author{
Diphallia in a bovine \\ Luiz Gustavo Schneider de Oliveira', Pedro Miguel Ocampos Pedroso', \\ Karine Ludwig Takeuti' ', Tatiane Terumi Negrão Watanabe', Hugo Henrique Ferreira', \\ Paulo Bender ${ }^{2}$ \& David Driemeier ${ }^{1}$
}

\begin{abstract}
RESUMO
Difalo, pênis duplo ou bífido é uma anomalia congênita rara que ocorre em animais e no homem, com escassos relatos na literatura. Este relato apresenta um caso de difalia em um bovino macho adulto castrado. A peça do sistema reprodutor de um bovino foi encaminhada por um frigorífico local para realização de exame histológico. O material foi analisado, fixado em formol $10 \%$, processado de forma rotineira para histologia e corado pela hematoxilina-eosina. Macroscopicamente, a peça apresentava duas glandes penianas, uma composta pelo corpo cavernoso, corpo esponjoso, uretra e prepúcio do pênis, sugerindo que esta fosse a parte normal. Adjacente a essa, havia uma formação tecidual idêntica à glande peniana, que, ao corte, no entanto, não se observavam uretra, corpos cavernoso e esponjoso. Ao exame microscópico das duas glandes, confirmou-se sua estrutura histológica, uma composta por corpo cavernoso, corpo esponjoso e uretra e a outra somente de tecido conjuntivo fibroso revestido por epitélio. O diagnóstico foi baseado nas alterações macroscópicas e constituição histológica característica. Esta anomalia pode prejudicar a micção assim como o desempenho reprodutivo do animal.
\end{abstract}

Descritores: difalo, bovino, anomalia congênita.

\begin{abstract}
Diphallus, double or bifid penis is a rare congenital anomaly that affects animals and human, which a few cases have been report in the literature. This report describes a case of diphallia in a bovine male, adult, castrated originating from a slaughterhouse that had two penile glands for histological exam. For microscopic examination, specimens were previously fixed in $10 \%$ formalin solution, processed routinely for histology and stained with hematoxylin-eosin. Macroscopically, duplication of glans penis in this bull was observed, one of them was composed with corpus cavernosum, corpus spongiosum, urethra and prepuce. Besides, one portion of tissue that reminds a glans penis was next the normal organ. Although, corpus cavernosum, corpus spongiosum, urethra did not find. In histological examination of the two glands, only one showing corpus cavernosum, corpus spongiosum and urethra and another one had fibrous connective tissue lined by epithelium. The definitive diagnosis was based on macroscopic and histological features. This congenital anomaly could cause difficult in urination, also, affect reproductive performance of this animal.
\end{abstract}

Keywords: diphallus, bovine, congenital anomaly. 


\section{INTRODUÇÃo}

Difalo, pênis duplo ou bífido é uma anomalia congênita rara [5], ocorre raramente em humanos, equinos, bovinos, ovinos, felinos e coelhos (espécie na qual a condição é herdada juntamente com Hydrops congenitus e Eritroblastose fetal) [2,3,8]. Segundo Roberts [7], as formas duplas do pênis, que, de acordo com o grau de divisão, podem variar desde uma duplicação da glande até dois membros completos, apresentando cada um sua uretra, assim como bexigas urinárias distintas. São denominadas Diphallus glandaris quando há divisão apenas da glande, Diphallus bifidus, quando há divisão parcial do pênis, e Diphallus totalis, quando existe divisão completa do membro [1]. Em humanos, é estimado que ocorra um caso de duplicação peniana a cada cinco milhões de nascidos nos Estados Unidos [2]. O objetivo deste relato é descrever a ocorrência de um caso de difalia em um bovino, já que se trata de uma anomalia relatada com pouca frequência em animais.

\section{RELATO DE CASO}

Foi encaminhada por um frigorífico local, uma peça de sistema reprodutor masculino de um bovino, ao Setor de Patologia Veterinária da UFRGS (SPV - UFRGS), para realização de exame histológico. Dados referentes ao bovino foram obtidos com o médico veterinário. O material foi fixado em formol 10\%, processado de forma rotineira para histologia, emblocado em parafina, cortado a $5 \mu \mathrm{m}$ de espessura e corado pela hematoxilina-eosina (HE) [6]. O bovino do presente relato era macho, castrado, sem raça definida e com cinco anos de idade. A peça ao exame macroscópico era composta pelo corpo cavernoso e corpo

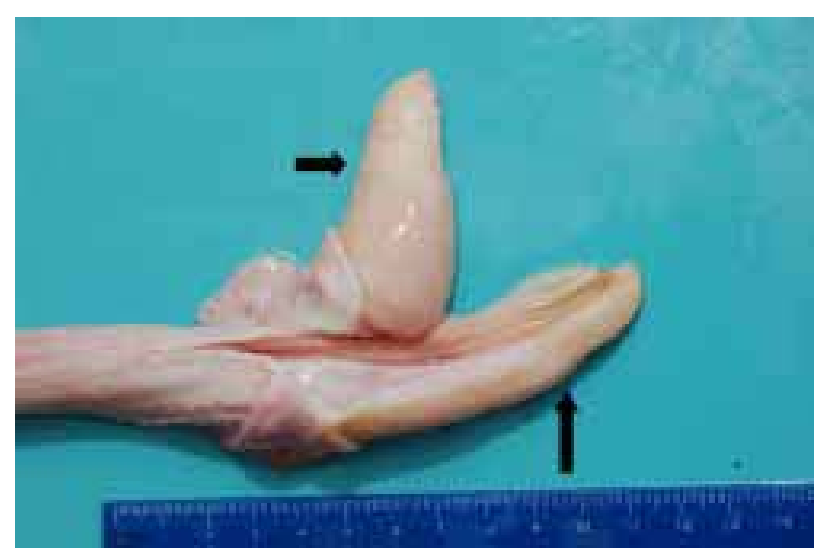

Figura 1. Difalia em bovino. Presença de glande peniana com uretra (seta maior) e outra glande sem uretra (seta menor). esponjoso do pênis, uretra, prepúcio e glande do pênis, sugerindo-se que esta fosse a parte normal. Ao lado desta, havia uma formação de tecido idêntica à glande peniana (Figura 1), porém, ao corte, não foi observado uretra e corpos cavernoso e esponjoso. Na histologia da glande normal, havia presença de uretra, corpo cavernoso e esponjoso (Figura 2), vasos sanguíneos e alterações como acantose e inflamação mononuclear. $\mathrm{Na}$ outra glande, havia somente tecido conjuntivo fibroso, pequenos vasos sanguíneos e revestido por epitélio (Figura 3).

\section{DISCUSSÃO}

O caso de difalia no bovino foi confirmado pela alteração macroscópica evidente e pela constituição histológica. Ao exame histológico, foi observado somente tecido conjuntivo fibroso e sem evidências de outros constituintes na formação da glande peniana,

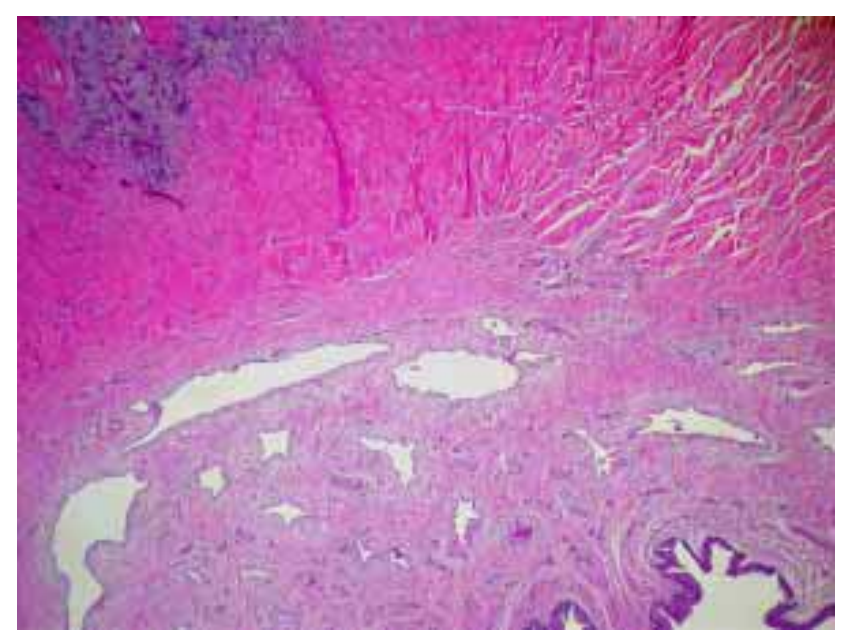

Figura 2. Glande peniana normal. Presença de uretra, corpo cavernoso e corpo esponjoso. Hematoxilina-eosina. (100x).

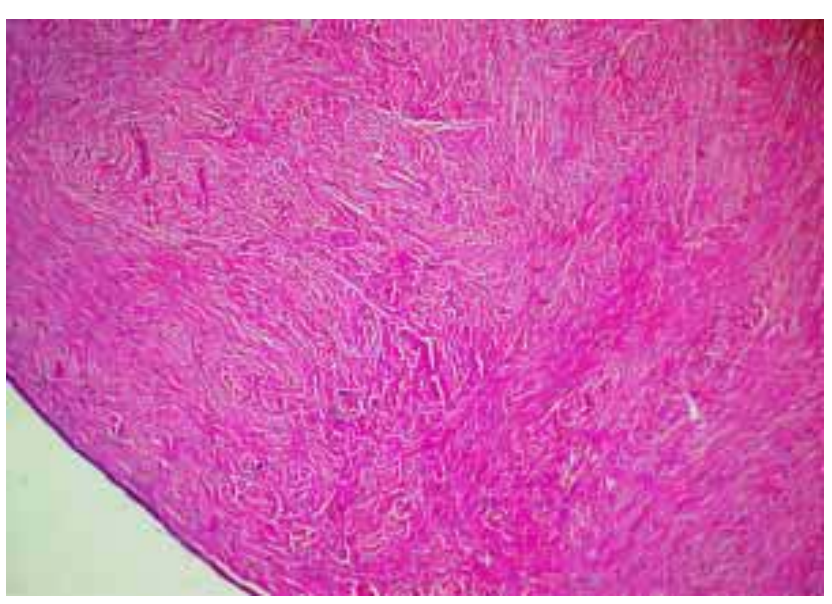

Figura 3. Bovino. Glande peniana constituída somente por tecido conjuntivo fibroso e revestido por epitélio. Hematoxilina-eosina. (100x). 
sendo semelhante à descrição mencionada em um caso de um humano de 31 anos de idade [4]. A duplicação confinada à glande peniana, como no caso observado, se enquadra como Diphallus glandaris [1]. Este animal do estudo era procedente de abate e sem fins de reprodução. Porém esta condição no macho prejudica tanto uma possível cópula como também a micção, consequentemente a vida reprodutiva do animal é comprometida.

Agradecimentos. Ao Conselho Nacional de Desenvolvimento Científico e Tecnológico (CNPq), pelo apoio financeiro.

\section{REFERÊNCIAS}

1 Busch W. 2001. Physiologie der Kopulationsorgane. In: Busch W. \& Holzmann A. (Eds). Veterinärmedizinische andrologie. Stuttgart: Schattauer Verlag, pp.166-169.

2 Dewan P. A., Lawrence M. J., Pip A. \& Kasa S. 1998. Diphallus associated with partial caudal duplication. Pediatric Surgery International. 14(1-2): 131-133.

3 Foster R. A. \& Ladds P.W. 2007. Male genital system. In: Maxie M.G. (Ed). Jubb Kennedy, and Palmer's Pathology of Domestic Animals. 5th edn. Philadelphia: Elsevier Saunders, v.3, p.611.

4 Gammie W.P. \& Davies J. H. 1988. Diphallus in an adult. British Journal of Urology. 62(2): 185-186.

5 McEntee K. 1990. Reproductive Pathology of Domestic Mammals. San Diego: Academic Press, p. 401.

6 Prophet E.B., Mills B., Arrington J.B. \& Sobin L.H. 1992. Laboratory Methods in Histotechnology. Washington: American Registry of Pathology, p.279.

7 Roberts S.J. 1943. Double penis in a Hostein bull. Cornell Veterinarian. 33: 388-393.

8 Weiss E. 2007. Geschlechtsorgane. In: Dahme E. \& Weiss E. (Eds). Gundriss der Speziellen Pathologischen Anatomie der Haustiere. 6th edn. Stuttgart: Enke, p.210. 